\title{
A Model Unknown Glass Engineered for EPMA WDS Quality Assurance
}

\author{
D. C. Meier, J. M. Davis, J. R. Anderson, and S. A. Wight
}

Material Measurement Laboratory, National Institute of Standards and Technology, Gaithersburg, MD 20899-8371

NIST presently uses a selection of metals, metal oxides, and mineral glasses, specifically K-411 and K-412 from SRM 470 [1], as material standards and model unknowns for its weekly quality assurance (QA) test measurement on its electron probe microanalysis (EPMA) wavelength dispersive spectroscopy (WDS) instrument. This suite of oxides and glasses, composed of $\mathrm{Mg}, \mathrm{Al}$, $\mathrm{Si}, \mathrm{Ca}$, and $\mathrm{Fe}$, is excellent for testing the full functionality of any spectrometer featuring a thallium acid phthalate (TAP) crystal, since the $\mathrm{Mg}, \mathrm{Al}$, and $\mathrm{Si} \mathrm{K}$ lines represent positions on the spectrometer that are nearly $100 \mathrm{~mm}$ apart. With a QA test in which a spectrometer traverses that range, issues such as dragging wires, systematic errors in position, and crystal defects can be readily identified provided the instrument is tested with the appropriate combination of peak vs. background measurements and wavescans. Unfortunately, the $\mathrm{Ca}$ and $\mathrm{Fe}$ that make up the remainder of the test suite provide only one element that is measured in a comparatively narrow range on either the pentaerythritol (PET) or the lithium fluoride (LiF) crystals, respectively, making troubleshooting spectrometers that contain those crystals considerably more difficult and the results of such tests less definitive.

The present work summarizes efforts to fill this void in the NIST EPMA QA program. An engineered glass has been developed to replace K-412 as the model unknown that generates characteristic X-rays strategically selected to maximize the specimen's analytical span of the WDS spectrometer for each of three common diffracting crystals (TAP, PET, and LiF). Such a glass will allow the analyst to produce both internal and intra-laboratory QA programs that cover most of the periodic table effectively using a single model unknown and standard specimen block capable of assessing the functionality of every spectrometer on the instrument simultaneously. Under electron beam excitation, this engineered glass (Figures 1 and 2) emits characteristic X-rays that include first order and second order diffraction lines for two characteristic $\mathrm{K}$ lines on each of the three major analyzing crystal types ( $\mathrm{Zn}$ and $\mathrm{Ge}$ on $\mathrm{LiF}, \mathrm{Ca}$ and $\mathrm{Ti}$ on PET, and $\mathrm{Si}$ and $\mathrm{Al}$ on TAP). This designed material allows for a more robust QA test of the LiF and PET spectrometers than the K-412 presently does. If the QA test fails on a given instrument, more comprehensive wavescans or peakand-background measurements that specifically test a suspect component can be performed using this glass, aiding in troubleshooting the specific problem with a crystal, a spectrometer, or the electron beam itself, thus reducing diagnostics and repair time.

[1] R. B. Marinenko (1982) Preparation and Characterization of K-411 and K-412 Mineral Glasses for Microanalysis: SRM 470. National Bureau of Standards Special Publication SP260-74. 


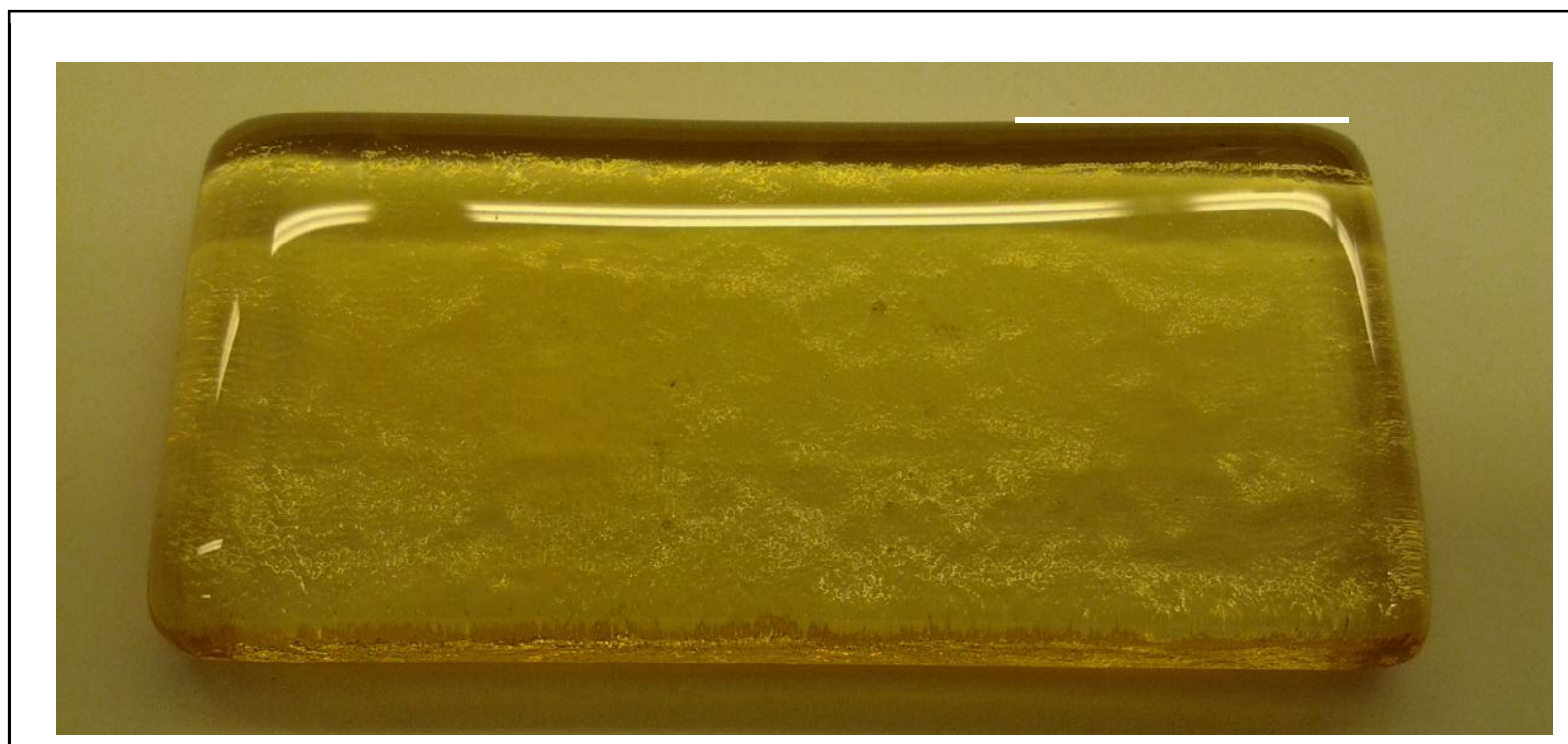

Figure 1. Photograph of a cast block of the engineered QA glass, a vitreous blend of $\mathrm{Al}, \mathrm{Si}, \mathrm{Ca}, \mathrm{Ti}, \mathrm{Zn}$, and $\mathrm{Ge}$ oxides.

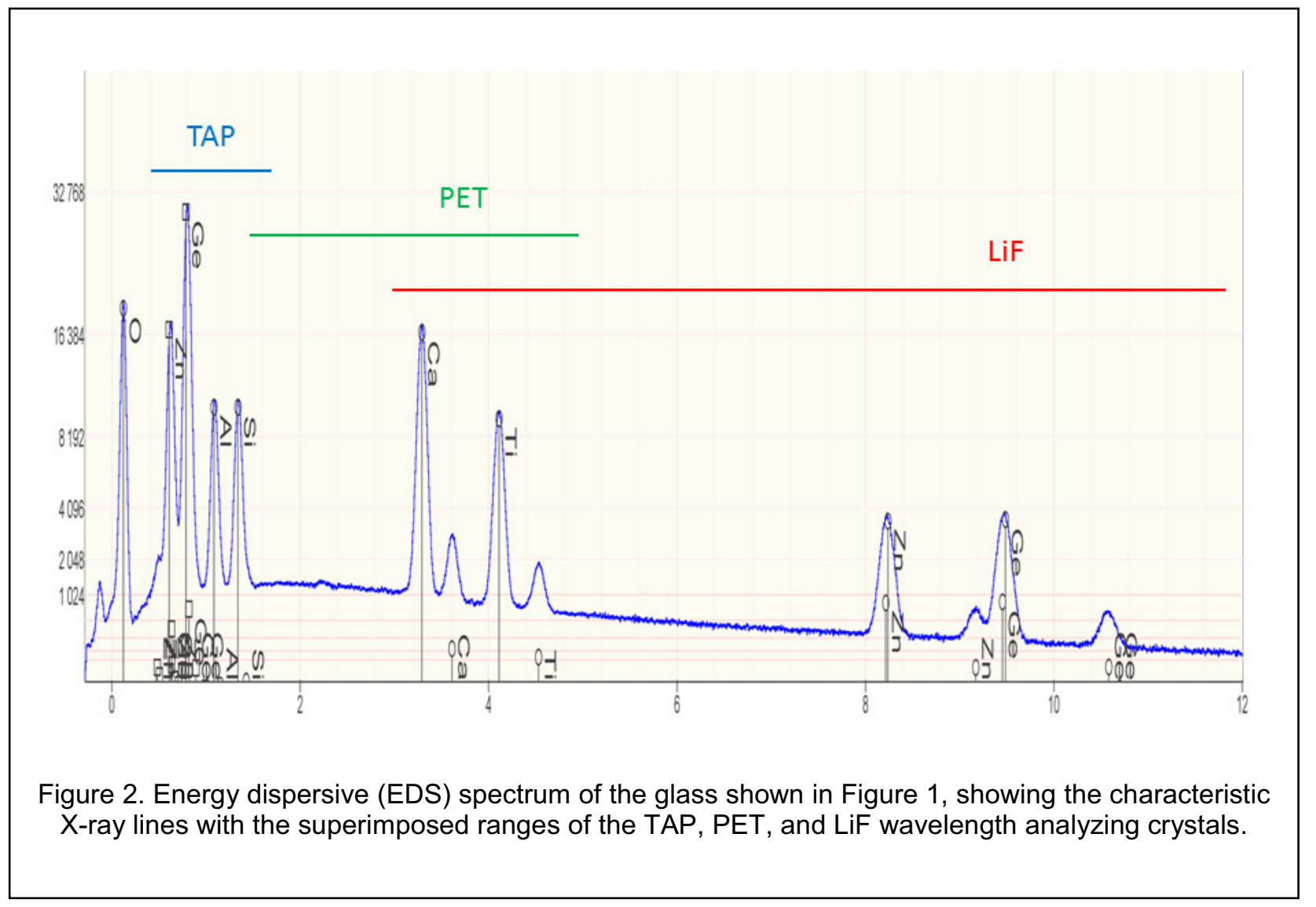

